\title{
Translation, Linguistic Analysis and Point of View: A Comparative Study
}

\section{Tradução, análise linguística e ponto de vista: um estudo comparativo}

\author{
Christiano Titoneli Santana*
}

\begin{abstract}
This article discusses the translation process in terms of point of view. The focus is Benjy, a character in the novel The Sound and The Fury by William Faulkner. To this purpose, two translations are compared with the original. The concepts of point of view by SIMPSON (1994) are discussed and descriptions of language by HALLIDAY and MATTHIESSEN (2004) are used as a framework of analysis.
\end{abstract}

Keywords: Translation; point of view; linguistic choices.

Resumo: Este artigo discute o processo de tradução com relação ao ponto de vista de Benjy, o personagem do romance 0 Som e A Fúria, de William Faulkner. Para tanto, duas traduções serão comparadas com o original. Serão discutidos os conceitos de ponto de vista (voz), segundo SIMPSON (1994), e serão usadas como pano de fundo as descrições acerca da linguagem de acordo com HALLIDAY e MATTHIESSEN (2004).

Palavras-chave: Tradução; voz; escolhas linguísticas.

\footnotetext{
* Mestrando em Estudos de Linguagem pela Universidade Federal Fluminense (UFF)
} 
SantanA, C. T. - Translation, Linguistic Analysis and Point of View: A Comparative Study

\section{Introduction}

As translation issues have had a long history, many theories and strategies have emerged to explain how translations occur and materialize. This work presents the perspective of two translators based on their linguistic realizations. It reports the result of analysis, discussion, and reflection stemming from studies, comparisons, and theories regarding literary translation, and linguistic descriptions.

This paper brings together thoughts and practice of almost five years in translation work. When the focus is on literary works, the strategies and techniques in translation are never enough to encompass the complexities of a translation. Our focus is on the implications and the translator's role regarding linguistic choices in the translation process, in this case: the point of view of the characters in a story. When we translate a novel, we may run the risk of being detached from the reality created originally. This is not due to our inaptitude or incapacity for bridging a link between two worlds. The problem resides in the fact that each language has its own way of revealing and establishing its world.

The present work compares two translations in Portuguese of the opening paragraph of Faulkner's The Sound and The Fury in order to check how they render the main character's point of view (SIMPSON 1994). The translations 0 Som e A Fúria, by Paulo Henriques Britto (2012), and by Fernando Nuno Rodrigues (197-) were analyzed through the lenses of functional systemic linguistics (HAlLIDAY, MATTHIESSEN 2004) and translation theories (BAKER 2006).

In order to carry out this investigation the three texts were scrutinized through functional systemic linguistics so as to bring out the experiential world they portray. Each sentence of the opening paragraph in each version was placed together and analyzed comparatively.

William Faulkner's novel was chosen because the issue of point of view is crucial as the novel explores four different perspectives of the same story. 
SantanA, C. T. - Translation, Linguistic Analysis and Point of View: A Comparative Study

The first perspective in the narrative is the one from Benjy, the main character, and the opening paragraph selected for this work presents his idiosyncratic view. When comparing the two translations, it is possible to see which one keeps the character's original perspective.

Methodologically, the point of view and linguistic issues are presented and discussed throughout the analysis. The analysis covers the investigation of each sentence translated and how the original idea is converted into Portuguese. Along with it, by looking at the linguistic choices, the meaning each translated sentence created and how each one conveys a point of view are discussed.

\section{Analysis and Discussion}

This section is focused on the theory weaved with analysis and discussion of the first paragraph of the novel The Sound and The Fury, by Faulkner. The original and two translated versions are examined in terms of point of view. The theoretical approach revolves around the functional grammar perspective, by HallidAY (1985), and HallidAY and MatTHIESSEN (2004). Thus, the analysis aims to investigate if the translator's interpretation covers the character's point of view properly in the light of Simpson's (1993) theory, and if to some extent the translation was distant or close to the original text, and what the linguistic realizations implied in the reading process.

In order to carry out the analysis, we will present the original sentence followed by two translations, one by Paulo Henriques Britto and the other by Fernando Nuno Rodrigues. The intention is not to evaluate the quality of the translation, but the mechanisms per se.

\section{1 Sentence by Sentence}


SantanA, C. T. - Translation, Linguistic Analysis and Point of View: A Comparative Study

\section{Sentence 1}

Through the fence, between the curling flower spaces, I could see them hitting.

(A) Do outro lado da cerca, pelos espaços entre as flores curvas, eles estavam tacando.

(B) Através da cerca, entre os espaços das flores, eu podia vê-los batendo.

This is the opening sentence of the novel with Benjy describing the scene of a golf game. It introduces Benjy's point of view as he sees something taking place before his eyes. Faulkner does not make it evident that this scene is a description of people playing golf. As VICKERY (1995: 30) states, “With Benjy we are restricted entirely to sensation which cannot be communicated". The readers are thus expected to read between the lines and to reconstruct the scene from the linguistic choices the author makes. In this sense, recreating the scene from the point of view of Benjy is to follow his report from his own perspective in the episode.

The first point to discuss is the prepositional phrase (PP) "through the fence", which indicates the place from where the character sees the scene. According to HallidAY and MATTHIESSEN (2004: 360-361), PP "consists of a preposition plus a nominal group [...], they cannot be reduced to a single element". In this context, the PP functions as an adverbial phrase of place because it modifies the verb. The PP head, "through", narrows the character's vision to a specific perspective of the setting. Its role is to link Benjy's vision to the clause "I could see them hitting" by implying a "limited point of view" (HIGH 1986: 154) from Benjy, who is mentally handicapped and cannot construe the characters' attitudes. In this phrase, Benjy's point of view is on a spatial plane, which "concerns the 'camera angle' adopted in a text, whether this be a 'bird's eye' view of events or the restricted viewpoint of a single observer" (SIMPSON 1993: 11). It means that this phrase invites the reader to experience the event from Benjy's viewpoint. 
SantanA, C. T. - Translation, Linguistic Analysis and Point of View: A Comparative Study

Let us consider the preposition "through". It presents two different versions. The first version translates it as "do outro lado", whereas the second one, as "através". Translator A (TA) goes beyond the meaning of the preposition by adopting "do outro lado". Firstly, contrary to the source language, this suggests that the character has a spatial notion of the place and knows the difference between opposite positions. Secondly, it seems the reader is invited to jump the fence and is positioned on the other side. This translator keeps the translation close to the spatial plane of Benjy's point of view, but distant in the degree of descriptive detail.

As SIMPSON (1993) states, we must consider point of view as a camera angle, and the closer the camera is, the more detailed aspects we are to see. TA brings more details than the original and adds new impressions to the reader going beyond what the character experiences. By choosing "através de", Translator B (TB) keeps close to the original in the spatial plane of the character's point of view and in the degree of descriptive detail. That means the reader is invited to be on the same side of the character, looking through the fence and not positioning himself beyond it. In this translation, the reader experiences the character's sensation of being an observer. In the light of translation at word level equivalence, BAKER (1992: 11) states that "there is no one-to-one correspondence between the orthographic words and elements of meaning within or across languages". In the case of "através de", the content maintains the equivalence in meaning close to the original.

The second point to investigate is the nominal group "the curling flower spaces" that is embedded within the prepositional phrase "between the curling flower spaces", that functions as an adverbial phrase of place. As presented by HaLLIDAY and MATTHIESSEN (2004), a nominal group consists of a head performed by a noun, functioning as "thing", and is made up of modifiers with different functions, such as deitic, post-deitic, numerative, epithet, and classifier. In the novel, all the components of the nominal group indicate the character's behavior as an observer and invite us to be in his role. The article "the" functions as a determinative deictic, which "indicates whether or not some 
SantanA, C. T. - Translation, Linguistic Analysis and Point of View: A Comparative Study

specific subset of the Thing is intended [...]" (HallidaY; MatthiesSen 2004: 312). This definite article shows that Benjy knows the place, assists him to describe the scene, and makes the reader imagine the flower as a barrier once Benjy is positioned to observe people playing golf. Being "an objective property of the thing itself" (op. cit. 318), the experiential epithet "curling" makes Benjy describe the kind of flower without naming it, but pointing out its natural traits due to his lack of vocabulary. In this case, the "flower", as a classifier, "indicates a particular subclass of the thing in question" (op. cit. 319), which can be pointed as "spaces", whereas "Spaces" function as a Thing, which "is the semantic core of the nominal group. It may be common noun, proper noun or (personal) pronoun" (op.cit. 325). This conflation of the classifier and the Thing helps Benjy construct his attempt to convey the meaning by three different modifiers to form the image of a flower.

Benjy's point of view, in "between the curling flower spaces", is built on a spatial plane; that means the readers have the impression of a filmic text, in which the character's movements to observe the scene incite the reader to take part of the story. In this phrase, "The suggested parallel with visual arts and particularly, filmic texts, is an important one; close-ups, long-shots and tracking shots all have linguistic counterparts in narrative fiction" (SIMPSON 1993: 11). These linguistic counterparts are connected to Benjy's linguistic choices that allow the reader to be the co-participant in the meaning construction of the story and to witness vividly the event registered through the character's particular mind.

In both translations $A$ and $B$, we can see that the adverbial phrase "between the curling flower spaces" differs sharply from each other. TA translates it as "pelos espaços entre as flores curvas", whereas TB translates it as "entre os espaços das flores". Linguistically, the first translation presents an embedded prepositional phrase with the function of adverbial phrase; in other words, "entre as flores curvas" is embedded within the first phrase "pelos espaços" (adverbial phrase). In the source language, however, there is only one 
SantanA, C. T. - Translation, Linguistic Analysis and Point of View: A Comparative Study

prepositional phrase "between the curling flower spaces". The second translation follows the author's choice with one prepositional phrase. This translation maintains the quantity of prepositional phrase and its function; however, the phrase produces a generalization. In spite of restricting the flowers by using the epithet "curling", the translator generalizes the term by omitting the adjective.

Concerning the point of view, both translations maintain the spatial plane except for the level of details. TA tends to obey more the character's narration by attempting to reproduce the lexica "espaços; curvas" to describe the flower, whereas TB does not imply that the character's vision is narrowed, interfered by the petals, and focused on the game.

Regardless of how close a text is to the original, these translations attempt to capture the original setting and the character in different ways. According to BAKER (1992: 86), "Differences in the grammatical structures of the source and target languages often result in some change in the information content of the message during the process of translation".

Regardless of these differences, both translations attempt to keep close to the source language in a certain way. TA keeps its syntactic structure distant from the original, but presents more equivalence in meaning, emphasizes more Faulkner's style in making Benjy's mind process the scene through his mental disorder. TB follows the syntactic structure between the original text, but keeps the meaning less detailed as the original brings out.

The third point to analyze is the clauses "I could see them hitting". They are made up of a finite clause, namely, "I could see them" - formed by a modal finite ("could"), where, within it, there is a nonfinite subordinate clause ("see them hitting"), and, eventually, there is "hitting" in the present participle as an object to the verb "see". This excerpt, for example, is interwoven by misuse of "hitting", a transitive verb used as an intransitive form; this aspect contributes to build the character's sensation and psychological limitation.

Another item is the object of the verb "see": "them", whose referent is not clear in the context. Most readers might question: "Who are they?", "What 
SantanA, C. T. - Translation, Linguistic Analysis and Point of View: A Comparative Study

are they hitting?" At once, the reader has the impression of being a child speech, which normally is fragmented and does not present any deep description, actually "[...] the author does not enter these novels, we, as readers, must join the game of speculation" (VOLPE 2003: 34). Faulkner makes the readers raise hypothesis about the setting; with a further reading, they perceive what "hitting" and "them" imply with some cultural details, such as the grass and the flag, and infer the collocational meaning of "to hit a (golf) ball" and "them" as a reference to "golf players".

The superficiality and gap in Benjy's speech make this excerpt more complex. The character's point of view is clearly on a spatial plane. As VICKERY (1995: 32) states, Benjy's observation is "a state of utter chaos for which the only possible justification is the fact that Benjy is an idiot and therefore has the right to be confused". That means the reader is obliged to notice the turmoil of perception in Benjy's mind and the manner in which he weaves his own reality.

The excerpt "I could see them hitting" is translated differently in both versions. TA translates it as "eles estavam tacando", and TB translates as "eu podia vê-los batendo". In TA, "eles estavam tacando", the personal pronoun "I" is replaced by the object pronoun "them"; the sentence is formed by just one finite clause without subordinate clause, and the clause "I could see" is thoroughly eliminated. The tense continues in the past. The verb "tacando" for "hitting" maintains the transitive verb used intransitively by the character; despite the translator attempting to seek an equivalent term, he gives away by implying this is a golf game, once we have the expression "tacar bolas de golfe". These excessive changes in translation transform the golf players into the main subject of the action and eliminate from the original Benjy's participation right at the beginning of the story. The translation of this clause changes the focus of the sentence and the interconnection with the previous phrases. That is why this change forces TA to translate the first prepositional 
SantanA, C. T. - Translation, Linguistic Analysis and Point of View: A Comparative Study

phrase "through the fence" as "do outro lado" to justify the position of the new subject of the clause "eles" (they).

Understanding is also compromised in the second phrase, "between the curling flower spaces", "pelos espaços entre as flores curvas", because this prepositional phrase does not link with the new subject's action. This second phrase causes ambiguity in Portuguese, because the reader is uncertain if they (the players) are on the other side hitting or if they are hitting among the curling flower. The second phrase becomes obscure in the first translation.

On the other hand, TB keeps close to the original in meaning and structure. The translator maintains both the pronoun "I" and the verbs by performing virtually the same role as in the source text. By opting for "batendo", TB also keeps the transitivity as in the source language, and renders the action from the point of view of the character, who is not aware that it is about a game. The character's problem is that he sees them "hitting" a ball for no reason. That is why "batendo" keeps closer to the character's point of view from a spatial plane. In this translation, there is no omission of the clause "I could see", translated as "eu podia vê-los". This conveys Faulkner's narration structure when the reader is taken to infer who is observing the scene, and what elements the scene is made up of. That means the two previous phrases, "através da cerca", and "entre os espaços das flores", continue to be inextricably linked with Benjy's performance and observation.

Both translations can be discussed from the textual equivalence perspective as explained by BAKER (1992), who is based on a Hallidayan approach to information flow. According to BAKER (1992: 121), theme is "what the clause is about", it has two functions, and here "it acts as a point of departure by connecting forward and contributing to the development of later stretches" (op.cit. 121). Rheme, however, is "the second segment of the clause [...] it represents the very information that the speaker wants to convey to the hearer" (op. cit. 122). In the excerpt "I could see them hitting", the theme is "I", in which Faulkner announces the topic of the message, whereas the rheme, "could see the hitting", is what the author has to say about it. On one hand, 
SantanA, C. T. - Translation, Linguistic Analysis and Point of View: A Comparative Study

TA is distant from the original because not only does he alter the sequence of the thematic structure, the theme and rheme, but he also crosses out Benjy's participation, creating a new actor of the action. On the other hand, TB maintains the theme and rheme strictly similar to the source text, giving the appropriate role to Benjy, performer of the action.

We can conclude that both translations provoke different reactions from the reader due to the production of distinct linguistic realizations in the translation act. Owing to the thematic structure, in the first translation the reader's participation is barely present, whereas in the second, as in the original, the reader becomes responsible in creating the scene. This suggests that, in the second translation, readers are expected to relate their schemata - previous knowledge - to the text on the attempt to interact with the linguistic choices that the author presents.

\section{Sentence 2}

They were coming toward where the flag was and I went along the fence.

(A) Eles foram para o lugar onde estava a bandeira e eu fui seguindo junto à cerca.

(B) Eles estavam vindo até onde a bandeira estava e eu fui ao longo da cerca.

In this second sentence, Benjy identifies the presence of people by describing their attitudes and following their actions. It describes the moment when Benjy moves from where he is and accompanies people's movements. He is not aware of what those movements stand for, but tends to reproduce the way the golf players move. Golf is a type of dynamic and active sport; we can conclude Benjy is not conscious that it is about a game specifically; through imitation he can dialogue with the world and represent his realm. As VICKERY (1995: 31) affirms, Benjy's report “merely presents snatches of dialogue, bits 
Santana, C. T. - Translation, Linguistic Analysis and Point of View: A Comparative Study

of scenes exactly as they took place". With these bits of scenes, we, as readers, start construing, by means of his linguistic choices, that the scene is potentially about a sport without discovering the game yet.

The first point to examine is "They were coming", which is the main clause, with the embedded clause "toward where the flag was". Based on HALLIDAY and MATTHIESSEN's (2004) viewpoint, clauses can be seen as message, exchange or representation. Analyzing the clause as message here means to look into it "As a message structure, therefore, a clause consists of a Theme accompanied by a Rheme; and the structure is expressed by the order whatever is chosen as the Theme is put first" (HallidaY, MatTHIESSEN 2004: 65). In the first clause, we have the simple theme "they" introduced and unknown by Benjy. As VICKERY (1995: 34) states, "Benjy does not know the names of these strangers and to give them an identity in terms of description is beyond his power". The use of the personal pronoun "they" here points that Benjy is unable to refer to a specific object or person and to describe it effectively. Benjy uses as rheme the structure "were coming". Together with it, the rheme is more narrowed down through the preposition "toward" that introduces the embedded finite clause "where the flag was".

To examine verbal groups on the grounds of experiential structure is, according to HallidaY and MATTHIESSEN (2004), to understand the relation between finite verbal group, possible auxiliaries and event. The experiential as well as the logic structures are stranded to the ideational component. That means the verbal group "were coming" is made up of a finite verb "were" plus the event "coming" labeled as nonfinite verb. In the case of the "where the flag was", the verb "was" functions as finite and event. To HaluidaY and MATthiesSen (2004: 336), event is the "act of consciousness or relation". Benj y's verbal choices are more focused on events. This reveals that the character has a limited concept of time and cannot measure the time itself by not using many auxiliaries and multiple tenses. Faulkner's narrative complexity is disclosed in the chronological aspect and, consequently, in the verbal groups. According to VolPE (2003: 30), we, as readers, think "beyond clock-measured time and 
SantanA, C. T. - Translation, Linguistic Analysis and Point of View: A Comparative Study

because what we do today is shaped by what happened yesterday [...]". That is why readers, at first, need to understand Benjy's mind, because for Benjy there is no concept of past, present, and future. The combination of this Sentence 2 with the previous Sentence 1 narrating the moment of the game demonstrates that all the events happen simultaneously in Benjy's mind, without having clock-measured time.

The second point to analyze is the excerpt "I went along the fence". Here we have the participation of the character in the setting as an observer and a performer. It is of great importance to notice how the verb "to go", as a finite verb, linked to the preposition "along" conveys the idea of Benjy's cooperation. This preposition suggests the character accompanies the dynamicity of the game taking into account the limit of the expansion of the fence. This scene implies Benjy does not know his role in that space, once he attempts to imitate the players' movements.

This sentence is clearly on a spatial plane. In this bit of scene, the reader starts perceiving that the character is observing a game, is expected to build the story and infer the actions involved in the scene. This complex text reveals Benjy's mental limitation because he cannot recognize the scene as a game; all the actions have the same level of importance and seem to happen at the same time. The reader is thus invited to reproduce Benjy's physical movement and experiences the character's agitation.

In TA, the clause "They were coming toward the flag was" becomes "Eles foram para o lugar onde estava a bandeira". The translator keeps close to the sequence of subject, verb and object; however, some elements are placed differently. The pronoun "they" [eles] indicates as in the original Benjy's uncertainty about the people on the other side of the fence. The verbs "were coming", in this case, are translated as "foram". We can notice that the content of the verb is translated idiomatically. In some cases, in Portuguese, the verb "come" indirectly suggests the contrary position "ir". TA keeps close to the original here because he understands this idiomatic difference. The 
SantanA, C. T. - Translation, Linguistic Analysis and Point of View: A Comparative Study

differences are that the verb is not in the progressive tense, but it remains in the past tense.

Besides, TA adds the term "o lugar" [the place] by emphasizing the adverb of place "onde" [where]. It is important to notice that the rheme "was" [estava] is fronted and topicalized in this translation, but remains as an intransitive verb. Another point to examine is "I went along the fence", that is translated as "eu fui seguindo junto à cerca". TA follows the same tense, but the verb changes to progressive mood. This alteration in the mood is because the preposition "along" implies a progression. However, the addition of a prepositional locution "junto à" goes beyond the original, and, as extra information, it suggests that Benjy is positioned near the fence.

In TB, in the clause "They were coming toward the flag was" [Eles estavam vindo até onde a bandeira estava], the verb "come" continues to be in the present participle and in the past tense, but we have to be attentive to the fact that the TB translates this verb literally as "vindo". This choice takes the reader to imagine that the golf players are going towards Benjy's direction and he is one of the players. It is evident the translator here creates this progressive action; unlike the original text, Benjy is not seen as an observer. However, in the verb "was" [estava], TB keeps close to the original when it is positioned after the subject "the flag" functioning as theme in the clause. In addition to it, the focus remains in the flag, and not in the place. In the case of "I went along the fence" [fui ao longo da cerca], TB limits the space and expansion as in the original, and this paints a picture of Benjy walking until the end of the fence.

Regarding point of view, TA and TB are on a spatial plane, but both bring different effects and thoughts to the reader's perspective. Both also invite the reader to share the setting with Benjy, but it brings a distinctive interpretation. TA brings the information that Benjy is conscious that he is following the players' attitudes and movements, whereas TB reports, as in the original, that Benjy goes along the fence to observe, but he does not have a clue about the people's action in that setting. 
SantanA, C. T. - Translation, Linguistic Analysis and Point of View: A Comparative Study

\section{Sentence 3}

Luster was hunting in the grass by the flower tree.

(A) Luster estava procurando na grama perto da árvore florida.

(B) Luster estava procurando na grama perto da árvore com as flores.

In this context, Benjy is observing Luster in the grass, but he is not aware of what Luster is looking for. The object, that is a golf ball, seems to be abstract for the character, because he is not able to see the connection between the people's movement and the main object in the scene. We, as readers, are put into the core of the story without any preparation here, and we are expected to organize and structure this fact by ourselves. In this excerpt, the reader is more likely to infer the context of a golf game.

In this sentence, there are two points to discuss. The first point is the finite clause "Luster was hunting" with the verbal group "was hunting" in the past progressive. According to HALLIDAY and MATTHIESSEN (2004), the verbal group begins with the Finite and ends with the Event, and both represent the lexical meaning. "Hunting" is the Event, which is the verbal equivalent of the Thing, and expresses an entity of some kind. Through this verb, we can notice again that Benjy uses an action verb without giving its proper object or complement; also, it denotes his primitive feeling once he cannot relate himself to the outer world. The second point to discuss is the phrase "in the grass by the flower tree". In this case, we have two PPs, "in the grass" is the main PP, functioning as an adverbial phrase of place. It is introduced by the preposition "in", "the" as a deictic word, and with the head "grass", labeled as Thing. In the embedded phrase, "by the flower tree", it starts with the preposition "by" introducing the noun group "the flower tree". This group has "the" as a deictic term, "flower" 
SantanA, C. T. - Translation, Linguistic Analysis and Point of View: A Comparative Study

as an epithet, and "tree" is embedded within the main phrase, with the function of adverbial phrase of place too. It is of paramount importance to observe that Benjy here can identify the space and Luster, his servant, at the same time, but he is not capable of inferring which action Luster is performing in the scene. It was as if he were able to realize all the parts of a situation but could not put all of them together because he did not understand the purpose itself. We can conclude that the whole sentence shown above reflects Benjy's point of view on a spatial plane. This is because the character opens the door for the readers to intervene in the story and to interact with the hints and steps that the author presents in the process of the narration.

To begin with, it is necessary to highlight that TA and TB in the sentence here discussed have close similarities in translation. Both translate "Luster was hunting" as "Luster estava procurando". It is indispensable to mention that TA and TB attempted to keep close to the original both in tense and mood. But we must consider Benjy's psychological limitation, once the most part of his mental process is based on primitive sensation and communication. Thus, it would be important to ponder over the translation of "hunt" as "caçar", which would cause the reader to experience the primary sensation when Benjy describes the episode. In respect to the PPs "in the grass by the flower tree", TA translates it as "na grama perto da árvore florida" that is divided into a PP and a prepositional locution differently from the source text. We have the main PP "na grama" ("na" [in the] = preposition "em" + deitic "a"; grass [grama] = head noun) with the function of adverbial phrase of place, and the embedded prepositional locution "perto da" [by the] that introduces the noun group "árvore florida" ("árvore" [tree] =head noun; "florida" [flower] =epithet). In TA's translation, we notice that it is syntactically distant from the original, but close to it semantically. There is no extra information, but the formation of the phrase relies on the Portuguese language. TB, in his turn, translates these phrases as "na grama perto da árvore com as flores", in this translation the syntactic structure is more different from that of the original, because we have "na grama" as the prepositional phrase, "perto da árvore", both cases detailed 
SantanA, C. T. - Translation, Linguistic Analysis and Point of View: A Comparative Study

above, and "com as flores" ("com" [with] = preposition; "as" [the] = deictic word; "flores" [flowers] = head noun) that is another embedded prepositional phrase. Unlike the source text, "com as flores" narrows down the type of flower through the deictic word "the"; this definite article implies that Benjy had mentioned about a specific flower. With this structure, TB makes the reader infer a different context, once he suggests that Benjy has the knowledge to specify a type of flower.

It is evident that Benjy is unable to understand the entire event and it is the readers' role to perceive the context behind the fragmented ideas of the character. The point of view is on the spatial plane as in the original, but TA and TB create different ways for the reader to follow. The readers develop different impressions and feelings when reading one of these translations, because they experience sensations that have not been expressed by the character originally.

\section{Sentence 4}

They took the flag out, and they were hitting.

(A) Eles tiraram a bandeira e aí tacaram outra vez.

(B) Eles tiraram a bandeira, e estavam batendo.

In this scene, Benjy plays the role of an observer describing the golfers' action detached from the setting and the context. To him, the action of taking a flag and hitting the ball is not interconnected. These actions are fragmented. He is not able to expand the essence of the situation in order to infer that it is a place where people are playing a game, and that hitting the ball and running are features of that game. In his mind, those people are performing different 
SantanA, C. T. - Translation, Linguistic Analysis and Point of View: A Comparative Study

activities for no reason. We can conclude that, at this stage, the readers clearly perceive that it is a golf game.

In Sentence 4, there are two points to discuss more deeply. The first point to examine is "took the flag out", that consists of the phrasal verb "take out". According to HallidaY and MatTHIESSEN (2004: 351), "Phrasal verbs are lexical verbs which consist of more than just the verb word itself"; the verb can be followed by particles called preposition or adverb, or both, they together produce a new and a different meaning. In this context, the separable phrasal verb "take out" means "to remove", it is a finite verb in the past by implying that Benjy seems to live mostly in his own world. As it is known, Benjy exaggerates the use of repetition. Again we have the clause "They were hitting", which is detailed and explained in Sentence 1. All in all, Sentence 4 is an illustration that his perspective on life is really unshaped by communication with others, as he is mute. This context also portrays Benjy's point of view on a spatial plane, once the readers are encouraged to enter his world to understand his shifting time. This becomes one of the most difficult aspects of Benjy's section in the novel because time seems to be irrelevant to him. For Benjy, important things are seemingly always present.

In the first clause "They took the flag out", TA and TB translate it as "Eles tiraram a bandeira". It is important to mention that both translations follow the mood and the tense. The phrasal verb "took out" becomes "tiraram". In Portuguese, this lexical verb does not exist and it requires a single verb to convey a meaning similar to the English version. Many phrasal verbs are seen as informal vocabulary. Benjy's speech revolves around the informality and primitive senses. In this translation, it could be used verbs such as "pegar", "apanhar", once they sound more like children's speech. But both translations do not fail to make evident the use of the past tense in an attempt to reproduce Benjy's shifting time.

In the second clause, "and they were hitting", TA and TB offer different translations. TA translates it as "e aí tacaram outra vez" and keeps the same translation for the verb "to hit" [tacar] used intransitively as in Sentence 1. It 
SantanA, C. T. - Translation, Linguistic Analysis and Point of View: A Comparative Study

is worth mentioning that in Sentence 4, TA does not follow the progressive aspect that Benjy uses to highlight the action and make it more real for him. Using the simple past in the translation makes Benjy distant as an observer, and in the original he is an observer who sees the scene before his eyes, even though he does not know what is happening in the setting properly. Unlike the source text, TA eliminates the personal pronoun "they". This does not follow Benjy's tendency to repeat virtually each word several times, and adds a discourse marker "aí" [then] and the adverb "outra vez" [again]. This addition in a way compromises the fidelity to the author's purpose. Benjy does not think chronologically and in sequence. As far as it is known, Faulkner does not cause Benjy to have the discretionary power to handle with time. Different from the original, this choice in translation implies that Benjy can evaluate people's action.

In TB, the second clause was translated as "e estavam batendo". The verb continues to have the same translation as Sentence 1 , in which it was detailed. It is of great importance that TB does not add any vocabulary item to this clause, but eliminates the personal pronoun "they". TB seeks to repeat the same tense and aspect - the past progressive - as an attempt to produce a counterpart of Benjy's quick sentences due to his limitation of vocabulary and feelings to express his inner world.

Concerning the point of view in Sentence 4, we can notice similarities and differences between both translations. The reality expressed by each one tends to differentiate in the second clause, and the reader's role is performed differently. Despite Benjy being more independent, judging the situation and mastering the chronology especially in TA, the point of view continues to be on the spatial plane, but it points to different directions of interpretation. On the whole, the spatial plane still functions to urge the readers to weave the story by their own by means of Benjy's world created by both translations.

\section{Sentence 5}


SantanA, C. T. - Translation, Linguistic Analysis and Point of View: A Comparative Study

Then they put the flag back and they went to the table, and he hit and the other hit.

(A) Então puseram a bandeira de novo e foram até a mesa, e ele tacou e o outro tacou.

(B) Então eles puseram a bandeira de novo e foram para o plano, e ele bateu e 0 outro bateu.

In this sentence, Benjy asserts his role as a "dependent observer", that is, there is a relationship between the character and Benjy that starts being bound. At this stage, the readers are more familiarized with the context based on Benjy's world, which presents a frequently repetitive vocabulary. The use of few words combined with repetition discloses the minimalist technique explored by Faulkner to make probably Benj y seem limited to fragmented mind and thoughts. Faulkner has the purpose of introducing Benjy's world to the reader by giving some backdrop of that context, so readers can complete the story by themselves.

Sentence 5 can be analyzed from three aspects. Firstly, we have the phrasal verb "put back", which is separable and functions as a finite verb. In the context, it seems that Benjy uses phrasal verbs with clearly understandable particles. In this case, the adverb "back" performs as a particle that does not have a strong idiomatic meaning and can be understood literally. Benjy resorts to semi-lexicalized phrasal verbs because idiomatic phrasal verbs are complex syntactically and require a deeper knowledge of the world around. Secondly, the other point to examine is the noun group "the table", which functions as an indirect object to the verb "to go to". The noun "table", in this excerpt, has more contextual meaning, and it goes beyond the first entry of the dictionary. According to the Merriam Webster's Collegiate Dictionary (2003), "table" also means "a horizontal stratum"; this is the sixth meaning in the entry "table", indicating this is not commonly used. Thirdly, there are the clauses "and he hit and the other hit". The verb "hit" was discussed and analyzed in Sentence 1, 
SantanA, C. T. - Translation, Linguistic Analysis and Point of View: A Comparative Study

but in the present sentence, we can observe the example of minimalism in the verb "hit". By minimalism, we understand it as an "impulse toward economy of expression" (MOTTE 1999: 1). This illustrates how Faulkner makes strong use of the spatial plane to build Benjy's point of view. By avoiding long sentences and using few verbs and objects, Benjy enables us to realize his limited perception toward the world and his lack of expression.

As to the translated versions, the first clause "Then they put the flag back", TA and TB offer almost the same translation. TA omits the personal pronoun "they". TA translates it as "Então puseram a bandeira de novo", whereas TB presents "Então eles puseram a bandeira de novo". In this first clause, both translations eliminate the function of the phrasal verb in English because this linguistic resource is not available in Portuguese. It is clear that both attempt to keep the simplicity and perception by following the syntactic structure of the original. However, readers can be led to different conclusions if we analyze the second clause, "and they went to the table". In the translation of "table", TA prefers "mesa", and TB, "plano", but both continue to be indirect object. Here it is important to understand Faulkner's purpose for the word "table". The author intends to use a primitive word to denote the idea of horizontal sphere where those golfers were located in order for them to hit the ball again. The generalization of that word describes Benjy as a human being unable to specify any situation deeply and to know its real objective. Thus, we can conclude TB achieves to express the essence of Benjy's characteristic, and TA uses the first meaning of the entry "table" and produces another interpretation for Benjy's attitude as an observer.

In the last two clauses, "and he hit, and the other hit", TA and TB keep their same choices as in Sentence 1 for the translation of "to hit". TA maintains "tacar", and TB, "bater". In these two clauses discussed, we notice that both produce the minimalist technique used by the minimalist Faulkner. "Through a reduction of means, minimalists hope to achieve an amplification of effect (MOTTE 1999: 4). This amplification is, therefore, exemplified by the verb "to 
SantanA, C. T. - Translation, Linguistic Analysis and Point of View: A Comparative Study

hit", which implies the socio-cultural aspect and context of the golf game along with the action of playing this game. The point of view continues to be on the spatial plane in both translations because both seek to draw the readers' attention to decode the fragmented perception of Benjy's life and take part in his reality in order to build their own concept on the story.

\section{Sentence 6}

Then they went on, and I went along the fence.

(A) Então eles andaram, e eu fui seguindo junto à cerca.

(B) Então eles foram, e eu fui ao longo da cerca.

This sentence is an illustration of Benjy as an observer and a participant. Throughout the opening paragraph, he plays the role of an observer without knowing the meaning of the scene. All the components of the setting are seen individually and not as a whole. As a participant, he attempts to follow the dynamic movements of the golfers, but because of his being mentally handicapped, Benjy reports the scene with few details and generalizations.

In Sentence 6, the first clause "Then they went on" is made up of a phrasal verb, and expresses a single meaning; therefore, "Experientially, a phrasal verb is a single Process, rather than Process plus circumstantial element" (HallidaY, MatThiessen 2004: 352). That means Benjy's reality boils down to a phrasal verb with a vague concept, because "to go on" suggests distinct meanings, such as "to continue"; "to persevere"; "to take place", and so forth. We can notice it is a finite verb in the simple past; readers are expected to understand "to go on" as the movement required to play the game. This establishes a connection with the following clause, "and I went along the fence", which is clarified in Sentence 2. In the second clause, Benjy senses he 
SantanA, C. T. - Translation, Linguistic Analysis and Point of View: A Comparative Study

must follow the agitation of the players, without construing his own condition as an observer. His attitude reflects his sensibility to realize the world around in terms of primitive feelings; however, he does not know what the situation is all about, and he tends to reproduce it inductively. Readers are encouraged to fill the gaps and vagueness of Benjy's perception. This reveals that the point of view in this context continues to be on the spatial plane.

Concerning the translation of the clause discussed above, TA and TB vary only in the interpretation and translation of the lexicalized phrasal verb "to go on". For this verb, TA opts for "andaram", whereas TB uses "foram". Both keep the past tense and the simple aspect. As shown in previous sentences, the Portuguese language does not offer phrasal verbs. Single verbs are more common to Romance languages. The particles after the verbs are required to align the complements, the direct and indirect objects to a sentence, but they do not change the meaning of the root verb as in English. In "andaram", TA indicates the action of walking that is not mentioned, but implied by the verb and the context. TB, in his turn, keeps closer to the source text because "foram" reproduces the same vague notion as in the verb "to go on". It implies Benjy is not conscious about the place he is situated and about what his context entails. It is the readers' role to conceive the golfers walking in the setting. As regards the second clause, TA and TB perform the same translation as in Sentence 2. It is of great importance to explain that, in the first clause, both keep the point of view on the spatial plane. TA encourages readers to know which action the players are taking, whereas TB guides readers to hypothesize the meaning under the phrasal verb discussed. Both translations invite readers to experience unique sensations; the experiential world of Benjy is thus reflected differently by these linguistic realizations.

\section{Sentence 7}

Luster came away from the flower tree and we went along the fence and they stopped and we stopped and I looked through the fence while Luster was hunting in the grass. 
SantanA, C. T. - Translation, Linguistic Analysis and Point of View: A Comparative Study

(A) Luster veio da árvore florida e nós seguimos junto à cerca e eles pararam e nós paramos e eu fiquei olhando através da cerca enquanto Luster procurava na grama.

(B) Luster voltou da árvore com as flores e nós fomos ao longo da cerca e eles pararam e nós paramos e eu olhei através da cerca enquanto Luster estava procurando na grama.

As the closing sentence, in Sentence 7, we have an overall idea of Benj y's attitude as an accidental observer. He observes the whole scene without understanding what those players are performing. He virtually summarizes the scene from the beginning of the paragraph until the end by using the same structures, such as repetition, short clauses without objects. Although being thirty-three years old, Benjy behaves as a child throughout the opening paragraph.

This last sentence offers three points for analysis. The first clause, "Luster came away from the flower tree", introduces a new and non-separable phrasal verb in the past tense. Phrasal verbs are considered complex lexical items, according to HallidAY and MATTHIESSEN (2004: 353), "There will often be doubt about whether these complex lexical items can be interpreted grammatically as a single Process or not". In any case, Benjy makes use of these verbs to express an informal idea as opposed to Latinate verbs, which require a more profound knowledge of the English language due to its peculiarity. The indirect object, "the flower tree", was explained and analyzed in Sentence 3 as well as the following clause "went along the fence". Both keep the same translation of the terms modifying only the personal pronouns. However, in the clauses "and they stopped and we stopped", we can notice the use of a finite verb in the simple past in a repeated way to amplify through reduction the effect of the movements in the game. It is important to notice the pronouns "they" and "we" are used vaguely, once Benjy inserts himself in the context of the game of which he is not aware. By "we", it can be implied he is replicating the golfers' movement dealing with it seriously because he is not able to 
SantanA, C. T. - Translation, Linguistic Analysis and Point of View: A Comparative Study

distinguish the reality from the game. Concerning the clause "and I looked through the fence", "to look" is a finite verb in the past tense followed by the particle "through". Together they do not constitute a phrasal verb. In this case, the meaning is totally literal and alludes to his eyes' movements. The last clause "Luster was hunting in the grass" is explained and detailed in Sentence 3. It portrays Benjy's fragmented ideas, primitive understanding, and incomplete thoughts.

Benjy's point of view remains on a spatial plane until the last sentence. As SIMPSON (1993: 11) states, "The expression 'spatial point of view' designates broadly the viewing position assumed by the narrator of a story". This means that, throughout Sentence 7 and the whole paragraph, Benjy, as a narrator, causes readers to see the whole scenario through his own eyes and perspective. Readers are exposed to a scenario without details. They have to weave the scene with the loose threads from Benjy's account.

Upon analyzing the translation of the phrasal verb in the clause, "Luster came away from the flower tree", TA presents the following clause, "Luster veio da árvore florida". TA follows the same word order as in the original, and it attempts to express Luster's action through a single verb. Thus, TA tends to make the readers experience almost the same sensation. In the original, it seems Luster was moving towards Benjy. The peculiar fact is that Benjy does not know his role in the scene: either as an observer, a participant, or both. $\mathrm{TB}$, however, translates the first clause as "Luster voltou da árvore com as flores"; in this translation, TB goes beyond the meaning of Benjy's speech. In reality, because he is mentally handicapped, Benjy is not able to distinguish the difference between "to go" and "to come back". Unlike the original, TB suggests that Benjy has the ability to understand that Luster was near the flower once, and he was coming back again for the second time. Benjy's notion of time is not clock-measured; he is guided by emotion. Grammatically, TA and TB keep the clause as the source text with a finite verb in the past tense. 
In the next clauses examined, "they stopped and we stopped", TA and TB translate it as "eles pararam e nós paramos". In this translation, both maintain the past tense in the simple aspect, as a finite verb; besides, they interpret it in the light of the original by not adding any other information.

Finally, the clause, "I looked through the fence", is translated by TA as "eu fiquei olhando através da cerca". In this translation, "fiquei olhando" differs from the original in its structure. "Fiquei" is a finite verb in the past tense as in the original. "Olhando" as a nonfinite verb. In the version by TA, he states indirectly that Benjy was observing the scene at a great length and as if he could identify all the people's functions. TB, in his turn, translates it as "eu ol hei através da cerca" and keeps the verb in the simple past and finite as in the original. Benjy's experiential world in TB's version is close to the source text, once it indicates that Benjy cannot keep his eyes on just one place. He changes his focus deliberately when there is nothing attractive to him.

In Sentence 7, the point of view is on the spatial plane, TA and TB accompany the point of view of the original, but they produce different realities due to their particular linguistic realizations. TA's and TB's versions lead readers to different interpretations and impressions. In some moments, TA and TB keep close to the original; in others, they are distant, this implies that translators ought to be very careful when wording their versions, as they will necessarily produce effects on readers that may or may not have been intended in the original.

\section{Final Considerations}


SantanA, C. T. - Translation, Linguistic Analysis and Point of View: A Comparative Study

As seen in the previous section, the analysis of the linguistic realizations of the two translations revealed some distinct points of view. This analysis means to evaluate how both translations are built in terms of linguistic choices and how the point of view is developed from the source text. In other words, this discussion is focused on the assessment of the results stemming from the translation act based on linguistic realizations, perspective, and point of view.

In the case of the opening paragraph of The Sound and The Fury, we notice through the analysis that most of the time both translators try to replicate the syntactic structures following the original. All seven extracts follow virtually the same syntactic order. They attempt to reproduce Benjy's mind. As illustrated in Sentence 1, both keep the phrases fronted. In terms of syntactic order, they respect Faulkner's style when not creating objects for transitive verbs which were used intransitively to show Benjy's disordered mind, as also shown in Sentence 1 in the clause, "I could see them hitting".

In the case of TA and TB, in some moments both translations highlight the same aspect of the story creating a different point of view through linguistic realizations. One example is Sentence 5 , in which the noun "table" is translated by TA as "mesa" and by TB as "plano". In TA's version, we have an example of how a translator can choose a term and make it distant from the original. We cannot say this is a mistake in terms of translation; actually, it is not appropriate to this context, in which "table" has another meaning, that is, it means a horizontal stratum. Sentence 1 in the phrase "curling flower spaces" is translated by TB as "espaços das flores", omitting the epithet "curling" and amplifying and generalizing the context. In this case, the reader will not be able to observe the scene as Benjy originally sees it.

It is important to bear in mind that it is through the linguistic realization, the point of view of the character, his or her perspective that the reader of this novel will construct the world. For the sake of illustration, the first clause of Sentence 2 was selected ("they were coming toward where the flag was"). TA translates "coming" as "foram" thinking of it idiomatically as we detailed in 
SantanA, C. T. - Translation, Linguistic Analysis and Point of View: A Comparative Study

Section 2.1. The problem resides in the fact that 'coming' in the original suggests Benjy is near the flag, and it implies he is behind the fence, and the golf players are heading the flag. Here the point of view differs from the original by changing Benjy's position. We can perceive that TA was probably worried about conveying the message, in a more idiomatic way, into Portuguese by making allusion to a similar idiomatic structure for the translation of "I' $\mathrm{m}$ coming" into "Estou indo".

It is not possible to say which translator keeps closer to the source text, as each one in a way makes different choices. We would commit a mistake if we evaluated a translation through (in)fidelity perspective, considered to be a traditional view. GADAMER (2010: 498), in his turn, states that each translation is an interpretation, because each one has his or her previous knowledge, social experiences, and cultural perspective. For illustration of different interpretations in the translation, in the sentence "They took the flag out", the phrasal verb is translated as "tiraram" by maintaining the generalization idea of the verb, instead of "arrancaram" that has a more specific meaning. According to BAKER (1992), a translation is also a matter of equivalence in different levels. Concerning levels, the most frequent level in both translations was the word-level.

It is interesting that both translations rely on point of view from a spatial plane, as shown and explained in the Analysis and Discussion sections. It indicates that TA and TB preserve the feature of Benjy as an observer despite their own particular linguistic choices. Naturally, the effects produced in the text will guide readers to different constructions, making them somehow experience a sensation different and detached from the source text. One example of this is Sentence 3, in which both translate "Luster was hunting" as "Luster estava procurando", since we know Faulkner's style was to keep the primitive sensations along with the childlike speech of Benjy. "Caçar" would be an alternative for the readers to clearly understand Benjy's behavior and his inaptitude for specifying and naming an action more profoundly. 
Benjy's experiential world is produced differently at some moments. As a brief illustration, in Sentence 1 ("I could see them"), TB presents "eu podia vê-los" as an alternative. "Vê-los" implies Benjy is mature, shows a good command of the language and consciously evaluates the situation. Here we see that Benjy is recreated in a different way. TB's choices allow the reader to imagine Benjy as a normal person, which differs from the source text, by giving him a new feature in the personality.

The intervention of the translator in a work is a constitutive aspect in a translation. AUBERT (1994: 81) observes that being a translator does not mean to be hidden or forgotten in a text, the translator is a producer of texts as well. We can add that, according to OTTONI (1997), the translator is influenced culturally, but also by his or her own language, that is, it is the language that enables the translator to have his choice in a relation of resistance between possibility and impossibility of conveying meanings. All in all, it is necessary to view the text as a product of an ideology and culture. Even readers of the source text will interpret and experience differently in the sense of having distinct views. Therefore, translation is the result of yet another interpretation.

\section{References}

AUBERT, F. H. As infidelidades da tradução: servidões e autonomia do tradutor. 2. ed. Campinas. Ed. Unicamp, 1994

BAKER, M. In Other Words. London: Routledge, 1992.

FAuLKNer, W. O som e a fúria. Tradução de Fernando Nuno Rodrigues. Círculo do livro, 197-.

O som e a fúria. Tradução de Paulo Henriques Britto. São Paulo: Cosac Naify portátil, 2012.

HallidaY, M. A. K., revised by MatThiessen, C. Introduction to Functional Grammar. London: Edward Arnold, 2004. 
SantanA, C. T. - Translation, Linguistic Analysis and Point of View: A Comparative Study

. An Introduction to Functional Grammar. London: Edward Arnold, 1985.

GADAMER, H. A linguagem como medium da experiência hermenêutica. In: Verdade e método I. Trad. Flávio Paulo Meurer. Petrópolis: Vozes, 1997.

Merriam-Webster's Collegiate Dictionary. 11th ed. Springfield, MA: MerriamWebster, 2003. Also available at http:// www. merriam-webster. com/.

MotTE, W. F. Small worlds: minimalism in contemporary French literature. University of Nebrasca Press, 1999.

OtTonı, P. R. A tradução é desde sempre resistência: Reflexões sobre teoria e história. Alfa: Revista de Lingüística (São Paulo), v.41, pp.159-68.

SIMPSON, P. Language, Ideology and Point of View. London and New York: Routledge, 1994.

VICKERY, O. W. William Faulkner: Contemporary Literary Criticism. Roger Matuz, 1995.

VoLPE, E. A Reader's Guide to William Faulkner: the Novels. Syracuse University Press Edition, 2003. 